\title{
Study on Digital Music Industry Operation in China
}

\author{
Zhiqiang Yin and Congyun Zheng \\ College of Music, Jiangxi University of Technology
}

\author{
Keywords: Digital Music; Industry Chain; Business Model; Development Strategy
}

\begin{abstract}
Since the 1980s, the rapid development of computer science and internet technology has brought profound reforms to the world. Digital music industry was born in this background, and it was the product of combination between traditional music industry and the new technology. Digital music has the advantages of low cost, high efficiency and personalized communication; it fits the demand psychology of consumers to cultural content products under the condition of new technology, and complies with the development trend of current cultural content industry; it has become the focus of cultural industry practice at home and abroad because of the rapid development in recent years. Digital music industry has great difference with traditional music industry in terms of business model and industry chain construction. The differences are not only the characteristics of digital music industry, but also reflect the common features of digital content industry with wider ranges, which contains the digital music industry. To study these features, this paper summarizes its inherent laws and finds out its development direction, which would be beneficial to the guidance of current cultural content industry practice. Combining with related concepts of economics, through data analysis and case comparison, the paper focused on the study of the laws of operation for digital music industry, systematically discussed the development of digital music industry, industry characteristics, industry chain structure, the business model, and the development strategy, aimed to find out the technical and social reasons behind the rise of digital music industry, analyzed the relationship of integrant parts of the industry chain, compared the similarities and differences, advantages and disadvantages, and development prospects of the different business model in the industry, pointed out the advantages and disadvantages, opportunities and threats facing in the development of this industry in China, and put forward the corresponding opinions and suggestions to the future development.
\end{abstract}

\section{Introduction}

Since the 1980s, the rapid development of computer science and internet technology has brought profound reforms to the world we are living in. Digital technology is infiltrating every aspect of our lives at an alarming speed, and has a significant impact on the development of human culture than any previous technological changes before.

Nowadays, the epoch-making technology has been widely used in media and cultural industries, and thus triggers the change of the whole industrial form. New propagation mode turnovers the business model of traditional music industry, highlights the huge profit potential and attracts the attention all around; however, due to the imperfect and immature business model, especially the backward protection methods of digital copyright, the digital propagation mode initially didn't bring too much benefits to the music industry, on the contrary, the music industry suffered great losses. Digital music industry is at the stage of frontier and focus of current digital content industry practice; 
it is the area of concern for both researchers of communication and economics. Theory comes from practice, and guides the practice. To promote the healthy and fast development of digital music industry in our country, scientific understanding is needed at first.

The spreading activities of digital music on the Internet began in the mid of 1990s, and the initial influences were mainly confined to a few netizens who were full of enthusiasm about online music communication; the ranges involved and the impacts on traditional record industry were limited, so it didn't attract much attention at first. In the 21 st century, with the rise of free music websites and the success in the field of wireless music, this new music propagation and sales way began to gain more attention inside and outside the industry.

Because of the economic system and social environment, the digital music industry in China has many specific characteristics, which demands that we must keep a foothold on the current reality, analyze and reorganize systematically the law of the occurrence and development in the industry, understand the status quo, focus on problems, and form theoretical achievements with practical and guiding significance. The study of digital music industry can not only significantly help the development of digital music industry theoretically and practically, but also inspire the development of other cultural industries under the new technology. The success and experience of digital music field can be completely applied into the development of other cultural industries, and help the overall development of cultural industry in China.

The Definition of Core. Simply speaking, the spread of digital music is to transfer the music into digital signal, and transfer the data through the channel of cyber space; users can download, store and appreciate through the information terminals, such as PC, handset, digital music player, etc.

The emergence of digital music broke the tradition. Digital music is stored in the database in the form of digital signals, and transferred in cyberspace. According to the requirement of users, the music can be downloaded and deleted, and the transmission no long relies on certain physical carrier.

Digital music industry is the collection of enterprises engaging in the production, transmission, sales service and relevant production and operation activities.

At present, the main components of digital music industry include record company, telecom operators, digital music service providers, electronic products manufacturers, technology developers, etc. The auxiliary and supporting system include relevant government departments, industry management agency, financial investors, and social survey institutions, etc. They jointly constitute the industry group.

In the digital music industry, the storage burden of music producers is gone because there is no record in the form of entity. Every song can make a profit, and there are no such problems as product backlog and difficult cost recovery even if no songs are sold. It has been nearly 10 years for the development of digital music in China; the digital music keeps up with the development speed in the world, and experienced several important stages of the world digital music development.

Because the specific national condition is different, there are some differences between the development of digital music at home and abroad. This is mainly embodied in two aspects: first, the digital music brings more opportunities than challenges in China; second, the road taken by China digital music industry is to pull the online music through wireless music.

In modern society, the economic environment is complicated; the foundation of enterprise operation is beyond the scope of a single enterprise's own ability and resources; every enterprise lives in the big industrial environment constructed by enterprise group and relevant industry group, and the environment is set in the industry chain on the basis of industry inside division and supply 
and demand relations. Industry chain is also called the industry value chain or ecological chain; the survival and development of enterprises and industries are closely related and mutually dependent, and any link plays an important role in the development of the whole chain. There is also such a chain in the field of digital music. In this chapter, we will understand digital music industry from the perspective of industry chain.

The theory of value chain told that commercial behaviors of single organization are always subord inate to a series of behaviors and a whole system rather than being isolated, and the concept of "industry value chain" is derived from the viewpoint. Industry value chain is based on some core value or technology, aims to provide utility system that can meet certain demands of consumers, and the optimal allocation and combination of resources with cohesive relations.

Potter, on the basis of the value chain theory, put forward the value chain analysis method, namely the enterprise activity decomposition, which is to determine the enterprise competitive advantage by investigating the activity itself and the relationship between each other. At the same time, Potter pointed out that the enterprise value chain is not isolated, but exists in the value chain system constructed by supplier value chain, enterprise value chain, channel value chain and buyer value chain.

The core of value chain theory is to explain the" structure meaning" and "dynamic meaning" of organizational behavior, which brings a new horizon to modern enterprise management, and urges enterprise operators and managers to hold the business activities in the more complicated relationship and from a more macro level.

Digital music industry chain is composed of content producers, telecom operators, service providers, equipment manufacturers, technology developers and users. These elements are distributed at the upstream and downstream of digital music industry chain, connected by value activities in correlation, and promote the development of the whole industry together. Due to the difference on product modality and communication channel with traditional music industry, the structure of digital music industry chain is also different.

Compared with traditional music industry chain, the structure of digital music industry chain is much more complex. It is made up of content producers, telecom operators, service providers, terminal equipment manufacturers, technology providers and end users. In the industrial chain:

1. Content providers include the record companies and individuals that can provide music content products in the downstream of industry chain

2. The role of music product manufacturers has retreated from industry chain due to non-entity transmission way of digital music

3. Telecom operators and service providers correspond to the issuing company in traditional music industry chain; telecom operators mainly provide network channel for music products distribution; service providers engage in the content integration and construction of point-of-sale terminal

4. Technology providers is the newly added link, which provide necessary technical support for normal operation in each link of the industry chain

5. Terminal equipment manufacturer amount to the player equipments manufacture in the traditional industry chain, but its role in the industrial chain is far more positive and important than the latter.

6. "Consumers" is replaced by "user" as users buy more intangible "services" rather than tangible products in the digital music; "user" reflects more characteristics of digital music.

To understand the overall structure and characteristics of the digital music industry chain, we will 
next make an analysis on the status, function and current situation of the elements in the industry chain, combining the development status of the industry in our country.

The content provider in the digital music ind ustry chain mainly refers to the record company with copyright, which is in the upstream of industrial chain, and has the largest share of profit sharing in the whole industry chain.

Digital music industry is part of the cultural content industry. The feature of cultural content industry is to produce and sell content products, and the department of original content is the core of the industry. Under the condition of digitization, the main duties and responsibilities of a record company are to provide content, which is not changed.

In the industry chain of digital music, the core value of record company is the music copyright possessed.

Digital music industry increases the sales platform for music content; multi-platform distribution is bound to cause shortage of content resource, which adds the negotiating point for record company. The digital music industry itself is built on the basis of technological progress. New technology is the soul of the industry. The role of technology provider for digital music distribution is to provide the necessary hardware equipment, software tools and network technology needed for the industry. These technologies and equipment help to realize the digitalization of music works as well as the processing of digital music, sales, reception, storage and appreciation.

The technologies applied for digital music industry mainly include the following three aspects:

First, the basic physical hardware include the construction of transmission network, which relies on the hardware facilities construction connected by LAN and WAN.

Second, the basic application technologies include various software tools designed for digital music, such as audio processing tools, virtual players, etc.

Third, the technology of digital copyright protection is one necessary condition to guarantee the healthy development of digital music industry. At present, the more advanced digital copyright protection technology is the DRM (Digital Right Management), developed by Microsoft; DRM can protect the music media files, and unauthorized music files; even if users copy the files into other machines, it won't be normally played due to not being authenticated.

The consumption demand of users is the foundation for the existence of industry chain. When it comes to the link of end users for digital music industry chain, the industry cycle is completed after the payment behavior occurs. Users of digital music are mainly composed of internet users and mobile users. The original digital music audiences are mainly confined to a few of the net enthusiasts and music lovers who own the multimedia PE, and now the number and scope have been greatly expanded with the rapid development of internet and mobile communication market around the world.

Of course, the business model is also very important. Business model is the integrated solution to maximize the customer value, by forming one complete and high-efficiency running system with unique core competence, integrating all the elements that can help the operation of enterprise and providing products and services for sustained profits of the system. To put it simply, business model is how to earn money from customers for enterprises.

According to the role of "content" and "technique" played in specific model, the existing digital music business models can be roughly divided into two types: the first type is "technology"- oriented, namely the enterprise belonging to the "technology" plate in the industry chain leads the development of industry; the second type is "content"-oriented, namely the content providers play 
the leading role in the industry chain.

At present, there are more than millions of users for digital music services provided by Taihe Rye, who is the absolute leader in China digital music field. In the selection activities of "China top 50 most valuable enterprises" sponsored by venture capital research authority in 2006, Taihe Rye was the only selected music company ranked 13th in the "China top 50 most valuable enterprises", and previously the company was selected as the "the best business model enterprise" by the magazine China Business Review. Critics believe that Chinese record companies, singers, music producers and songwriters have begun to gain real benefits via internet because of the "digital music distribution alliance" of Taihe Rye. The marketing model of the business alliance has provided a feasible development direction for both technology and profit model.

In order to promote the development of digital music industry in China, we need to first understand the reality clearly, and propose reasonable and operational strategies and suggestions. Therefore, we should make an objective analysis on internal and external environment to our digital music industry by the way of SWOT at first.

For the development, each link of the industry chain should play their expertise, cooperate and make progress together; "Digital music distribution alliance" realized that. In "digital music distribution alliance", every business has their own responsibilities and functions, for example, Taihe Rye is the content provider, and responsible for providing high quality music products for alliance; China mobile wireless music charts and China mobile make use of the wireless value-added services with mature market experience, and provide high-efficiency and convenient service for digital music through customization of ring back music, WR, Speaker P; on the internet platform, Taile website provides digital copyright certification, TOM, Sohu, Tencent and Taile provide sales service, and Baidu provides piracy intercept and marketing support; moreover, Microsoft offers a comprehensive technical solution.

According to the above analysis, the current policy environment is in favor of the development of digital content ind ustry, but the immature development is also highlighted. Based on these conditions, we proposed some strategies to help the digital music industry make use of advantage, overcome the weakness, seize the opportunity and avoid threats, so as to promote the all-round development of the industry.

\section{Conclusions}

The digital music industry is still growing around the world. As the important part of new digital content industry, it has great impact on the culture and entertainment.

The advent of the era of digital music is based on the continuous progress of communication technology. The rapid development of the industry benefits from the prosperity and stability of national economy. The growing popularity of the broadband and rapid growth of the number of internet users and mobile phone users has created broad market for the industry. At present, the more mature business model tested by the market has been established in the field of wireless digital music; the field of online digital music also has improved a lot on the condition that the business mode is increasingly mature, the digital copyright control technology is increasingly perfect, industry self-control ability is constantly improved and government departments intensify the support.

The paper built a rough research framework for digital music industry, and conducted a systematic elaboration to the industry from the aspects of development course, ind ustry characteristics, industry chain structure, business model, and development strategy. However, due to limited research and 
references on this field as well as the limitation of the individual ability and space, the framework is not that perfect, and some points are not fully discussed. For example, on the business model of digital music, the paper listed the technology-oriented model and content-oriented model, which was far from the richness of reality; on the crossover and connection of industry chain and business model, the paper didn't give clear definition and analysis; on the important influence and development status of wireless music, the paper didn't fully discuss; these are all the deficiencies of the paper. The author would like to continue to focus on, further enrich and extend the research of the paper in the coming days.

\section{References}

[1] Dedrick J, Kraemer K L, Linden G. Who profits from innovation in global value chains?: a study of the iPod and notebook PCs[J]. Industrial and Corporate Change, 2009: dtp032.

[2] Lysonski S, Durvasula S. Digital piracy of MP3s: consumer and ethical predispositions[J]. Journal of Consumer Marketing, 2008, 25(3): 167-178.

[3] Graham G Burnes B, Lewis G J, et al. The transformation of the music industry supply chain: A major label perspective[J]. International Journal of Operations \& Production Management, 2004, 24(11): 1087-1103.

[4] Liu J. The tough reality of copyright piracy: a case study of the music industry in China[J]. Cardozo Arts \& Entertainment Law Journal, 2010, 27: 621.

[5] Parry G, Bustinza O F, Vendrell-Herrero F. Servitisation and value co-production in the UK music industry: an empirical study of consumer attitudes[J]. International Journal of Production Economics, 2012, 135(1): 320-332.

[6] Fung A Y H. Global capital, local culture: Transnational media corporations in China[M]. Peter Lang, 2008.

[7] Throsby D. The music industry in the new millennium: Global and local perspectives[J]. Global Alliance for Cultural Diversity. Paris: UNESCO-Division of Arts and Cultural Enterprise, 2002.

[8] Montgomery L, Fitzgerald B. Copyright and the creative industries in China[J]. International Journal of Cultural Studies, 2006, 9(3): 407-418.

[9] Thussu D K. Media on the Move[J]. Global flow and contra-flow. S, 2007.

[10] Hill C W L. Digital piracy: Causes, consequences, and strategic responses[J]. Asia Pacific Journal of Management, 2007, 24(1): 9-25. 